\title{
RESPONSE OF RHIZOBIAL STRAINS ON BIOCHEMICAL TRAITS AND NUTRIENT UPTAKE IN MUNGBEAN (VIGNA RADIATA L. WILCZEK) UNDER MOISTURE STRESS
}

\author{
Sapna $^{1 *}$ and K. D ${ }^{2}$ Sharma \\ Department of Botany and Plant Physiology \\ CCS Haryana Agricultural University, Hisar -125004 \\ * sapnayadav173@gmail.com
}

\section{Abstract:-}

The present study was conducted to assess the biochemical responses and nutrient uptake in response to rhizobial inoculations in mungbean, and to screen the rhizobial isolates for drought tolerance. A field experiment was designed in randomized block design and replicated thrice during kharif 2016 at Crop Physiology Field Area, CCS, Hisar. The experiment consisted of two levels of treatments (1) without inoculation (only RDF) and (2) with inoculation (RDF with combination of five rhizobial strains viz. Vigna 703 + PSB strain P-36, MR 63, MR 54, MB 17a and $\mathrm{MH} \mathrm{8b2)}$ and two environments i.e. rainfed (no post sowing irrigation) and irrigated. Membrane stability index, leghaemoglobin content, chlorophyll content reduced by $17.7 \%$, $24.5 \%$ and $2.9 \%$ resp. under rainfed conditions while the plants inoculated with rhizobial isolate MR63 and MB 17a showed greater chlorophyll content $(20.2 \%$ and $16.2 \%)$, LHb (29.1\% and $22.9 \%)$ and MSI (19.4\% and 17.9\%) and enhanced nutrient uptake over RDF.

Keywords: Biochemical traits, drought, mungbean, nutrient, rhizobia

\section{Introduction:}

\footnotetext{
${ }^{1}$ Sapna

Ph.D Scholar, Botany and Plant Physiology, CCSHAU, Hisar, 8901217670

${ }^{2}$ K.D Sharma

Principle scientist, Botany and Plant Physiology, CCSHAU, Hisar, 9416397543

This paper is the part of MSC thesis submitted to CCSHAU, Hisar,125004

[Type text]
} 
Mungbean is one of the $3^{\text {rd }}$ most important legume after chickpea and pigeon pea. It is a vital source of protein, carbohydrates, minerals, fibers, antioxidants like flavonoids (Quercetin-3Oglucoside) and phenolics for vegetarian in dietary habit (Guo et al., 2012). It is a short-duration legume (<65 days), that makes it an ideal crop for catch cropping, relay cropping and intercropping. Despite being an economically important crop, overall production of mungbean is low due to abiotic and biotic stresses (Bangar et al., 2018). Among the various environmental stresses, the major factor limiting the crop yield is the amount of moisture available to the crop during the growing season. In India, about $68 \%$ of net sown area (140 million hectares) is reported to be vulnerable to drought conditions. Mungbean when cultivated in post rainy season faces water stress at various stages of crop growth (Rambabu et al., 2016). The effects of water stress in mungbean has been found to be more pronounced on reproductive stage than other growth stages and yield is drastically reduced (Majeed et al. 2016).

Water stress affects various physiological processes associated with growth, development, and economic yield of a crop (Reboucas et al., 2017). Water deficit alters normal uptake of different essential nutrients that causes reduced plant yield. Cell membranes are one of the first sites of damage and it is generally accepted that the maintenance of their integrity and stability under water stress conditions is a major indicator of drought tolerance in plants. The occurrence of stress indicated by cell membrane injuries leads to an increased leakage of electrolytes (Tint et. al., 2011). Chlorophyll is the main chloroplast component for photosynthesis and substantial chlorophyll content has a constructive association with photosynthetic rate (Shobhkhizi et al. 2014). A study by Mafakheri et. al. (2010) indicated that, water deficit results in negative impact in plants as majority of chlorophyll are lost. 
Rhizobia influence the physiological growth conditions of mungbean by nitrogen-fixing symbiosis and thus increasing its chlorophyll contents (Anjum et. al. 2006). However, $\mathrm{N}_{2}$ deficiency give a negative response in plants by showing symptoms of yellowing which demonstrate chlorophyll deterioration has occurred in plants. The bacteria lodging around the plant roots (rhizobacteria) are also more versatile in transforming, solubilizing and mobilizing other essential nutrients compared to those from bulk soils (Hayat et al., 2010). Therefore, the rhizobacteria are the dominant deriving forces in recycling the soil nutrients and consequently, they are crucial for soil fertility (Glick, 2012). Keeping in view numerous manifestations of a beneficial action of Rhizobium bacteria on plants, present investigation screens the various rhizobial strains in terms of biochemical traits and nutrient uptake in Mungbean (Vigna radiata L. Wilczek) under moisture stress.

\section{Materials and Methods:-}

A field experiment was conducted during the rainy (kharif) season of 2016 in the drought plots at Crop Physiology Field Area, Department of Agronomy, CCS Haryana Agricultural University, Hisar (Haryana) in western side at $29^{\circ} 10^{\prime}$ North latitude, $75^{\circ} 46^{\prime}$ East longitude and at an altitude of 215.2 metres above mean sea level. The plot size for each treatment was $2.5 \times 1.8$ $\mathrm{m}$ ( six rows of $2.5 \mathrm{~m}$ length with $30 \mathrm{~cm}$ spacing) with rainout shelters facilities. The soils had alkaline $\mathrm{pH}$ (8.60), available Nitrogen $112.7 \mathrm{~kg} / \mathrm{ha}$ and available Phosphorus $12.0 \mathrm{~kg} / \mathrm{ha}$. Mungbean rhizobial isolates were procured from Department of Microbiology, CCS Haryana Agricultural University, Hisar and the seed inoculation was done 2-3 $\mathrm{h}$ before sowing. The experiment included 6 treatment combinations (RDF and rhizobial strains) i.e. Recommended dose of fertilizer (RDF), RDF + Rhizobium sp.(vigna)703 + PSB strain P-36, RDF + MR 63, $\mathrm{RDF}+\mathrm{MR} 54, \mathrm{RDF}+\mathrm{MB} 17 \mathrm{a}$ and $\mathrm{RDF}+\mathrm{MH} 8 \mathrm{~b} 2$. The variety MH-421 of mungbean was used as the test crop and the sowing was done on $27^{\text {th }}$ June, 2016. Recommended dose of 
fertilizers (20 $\mathrm{kg} \mathrm{N}$ and $40 \mathrm{~kg} \mathrm{P}_{2} \mathrm{O}_{5}$ ) and crop protection measures was adopted as per package and practices.

Leaf discs $(0.05 \mathrm{~g})$ were washed, blotted dry and dipped in test tubes containing $5 \mathrm{ml}$ of dimethyl sulfoxide (DMSO) overnight as described by Sawhney and Singh (2002). The extracted chlorophyll in DMSO was estimated by recording its absorbance at 663 and $645 \mathrm{~nm}$, respectively

The assessment of membrane stability was done by the procedure of Dionisio-Sese and Tobita (1998). $100 \mathrm{mg}$ of leaf tissue was taken separately in $20 \mathrm{ml}$ test tubes containing $10 \mathrm{ml}$ of de-ionized water and kept in $20 \mathrm{ml}$ vials containing $10 \mathrm{ml}$ de-ionized water at $25^{\circ} \mathrm{C}$. After $4 \mathrm{~h}$, the electrical conductivity (EC) of the solution was measured and designated as $\mathrm{EC}_{\mathrm{a}}$. Then the samples were kept in boiling water bath for $1 \mathrm{~h}$ to achieve total killing of the tissue. After cooling, the EC of the solution was again measured and designated as $\mathrm{EC}_{\mathrm{b}}$.

Leghaemoglobin ( $\mathrm{LHb}$ ) was determined by the method of Hartree (1995) with some modifications. This method was based on the conversion of haematin in pyridine haemochromogen. The whole plant nodules of known weight were homogenized in $5.0 \mathrm{ml}$ of chilled 0.1 M phosphate buffer ( $\mathrm{pH} 7.0)$ in pestle mortar placed in ice bath. The extract was centrifuged at $5000 \mathrm{ppm}$ for 30 minutes. At $4^{\circ} \mathrm{C}$ on refrigerated centrifuge $5.0 \mathrm{ml}$ of supernatant was used for leghaemoglobin estimation.

The content of nitrogen and phosphorus were estimated in the seeds and stover of plant after harvesting. Digestion of plant material was done by adding di-acid mixture $\left(\mathrm{H}_{2} \mathrm{SO}_{4}: \mathrm{HClO}_{4}\right.$ in 9:1 ratio). The nitrogen content was determined by using the method as Lindner (1994) and the phosphorus content was determined by vando-molybdophosphoric acid yellow colour method as described by Koenig and Johnson (1942). 


\section{Results and Discussion:-}

Results presented in Table 1 showed the total chlorophyll content decreased (2.9\%) under water stress over irrigated. Such decrease in chlorophyll content in the leaves of plants may be attributed to the high rate of chlorophyll degradation more than its biosynthesis under water stress conditions (Raina et al. 2016). Application of rhizobial isolates increased the total chlorophyll content and the increase was more in RDF + MR 63 (4.91 mg/g/FW) followed by $\mathrm{RDF}+\mathrm{MB} 17 \mathrm{a}(4.70 \mathrm{mg} / \mathrm{g} / \mathrm{FW})$ over RDF (3.91 mg/g/FW). The increased chlorophyll in rhizobial inoculated treatments may be due to improved plant water status resulted in reduced chlorophyll degradation and enhanced chlorophyll formation. Similar effect of rhizobial treatments on chlorophyll content was observed by Tairo et al. (2017)

The results revealed that membrane stability index (MSI) significantly decreased during water stress (17.38 to $14.7 \%$ ) as presented in table-1 might be due to reduced cell water potential. Our result is in agreement with the findings of previous researchers who suggested that membrane integrity and stability are two important factors contributing to drought tolerance capacity and yield stability of crops (Diego et al. 2012). Among the rhizobial isolates, RDF + MR 63 showed maximum membrane stability (19.4\%) followed by RDF + MB 17a (17.9\%), while, the minimum MSI was observed in plants treated with RDF (11.9\%) accompanied by $\mathrm{RDF}+$ Vigna703+ P-36 (14.0\%) irrespective of the environment. The results indicated that inoculation with rhizobium spp. gives tolerance to plants under drought stress, because the permeability of inoculated crops decreased under drought stress. The lowest reduction of MSI in rhizobial strain MR 63 and MB 17a revealed its higher capacity to tolerate the adverse effects of drought. The similar effect of rhizobium inoculation on $P$. vulgaris under drought was also reported by Quinto et al. (2015). 
Highest leghaemoglobin content in root nodules was recorded in plants grown under irrigated condition $(2.23 \mathrm{mg} / \mathrm{g} \mathrm{DW})$ as compared to rainfed $(1.68 \mathrm{mg} / \mathrm{g} \mathrm{DW})$ at the flowering stage (Table 1). Water stress induced onset of nodule senescence may probably be responsible for decline in leghaemoglobin content and consequently inhibition of $\mathrm{N}_{2}$-fixation (Kumar and Kuhad, 2003). Among the treatments, the highest value of leghaemoglobin content was observed in rhizobial strain MR $63(2.34 \mathrm{mg} / \mathrm{g} \mathrm{DW})$ followed by MB 17a (2.16 mg/g DW). The leghaemoglobin content in RDF was lowest $(1.66 \mathrm{mg} / \mathrm{g} \mathrm{DW})$ and was at par with Vigna $703+\mathrm{P}$ $36(1.75 \mathrm{mg} / \mathrm{g} \mathrm{DW})$ and RDF + MH 8b2 (1.89 mg/g DW). Our results are in accordance with the findings of Rodrigues et al. (2013) who reported the similar increase in LHb in response to rhizobial inoculations.

\section{Nitrogen and phosphorus content}

Water stress significantly decreased the nitrogen and phosphorus content in both seed and straw over normal irrigation (Table 1). Decrease in $\mathrm{N}$ and $\mathrm{P}$ content under moisture stress from $3.69 \%$ to $3.54 \%$ \& $0.40 \%$ to $0.24 \%$ and $2.13 \%$ to $1.22 \%$ \& $0.15 \%$ to $0.11 \%$ in seed and straw resp. over the irrigated control, irrespective of the rhizobial treatments. . Nutrients from the soil reached to the surface of root by mass flow and diffusion processes. Mass flow and diffusion processes are positively correlated with moisture content of the soil. Movement of nutrients thought the plant is also associated with soil water content (Khaton et al., 2016). Thus, the greater content and uptake of $\mathrm{N}$ and $\mathrm{P}$ in seed and straw was observed under irrigated environment as compared to rainfed. Our results are supported by the findings of Ali et al. (2016) and Mohammad et al. (2017). Maximum nitrogen and phosphorus content was $3.96 \& 0.43 \%$ in seed and $1.93 \&$ $0.16 \%$ in straw observed in plants treated with rhizobial isolate MR 63.

Conclusion: In the present study, the five rhizobial isolates namely Vigna 703 + PSB strain P36, MR 63, MR 54, MB 17a and MH $8 \mathrm{~b} 2$ were evaluated for drought tolerance using 
biochemical traits and nutrient uptake in seed and straw. Based on the findings of this experiment, plants inoculated with rhizobial isolate "MR63 and MB 17a"shows greater chlorophyll content (20.2\% and 16.2\%), LHb (29.1\% and 22.9\%) and MSI (19.4\% and 17.9\%) and enhanced nutrient uptake over RDF

\section{References:}

1. Ali, Q., Haider, M.Z., Iftikhar, W., Jamil, S., Javed, M.T., Noman, A., Iqbal, M. \& Perveen, R. (2016) Drought tolerance potential of Vigna mungo L. lines as deciphered by modulated growth, antioxidant defense and nutrient acquisition patterns. Brazilian Journal of Botany, 39: 801-812.

2. Anjum, M.S., Ahmed, Z.I., Rauf, C.A. (2006) Effect of Rhizobium inoculation and nitrogen fertilizer on yield and yield components of mungbean. Int. J. Agric. Biology, 8(2): 1560-8530.

3. Bangar P, Chaudhury A, Umdale S, Kumari R, Tiwari B, Kumar S, Gaikwad AB, Bhat KV (2018). Detection and characterization of polymorphic simple sequence repeats markers for the analysis of genetic diversity in Indian mungbean [Vigna radiate (L.) Wilczek]. Indian J Genet Pl Br 78: 111-117.

4. Diego, N., Pérez-Alfocea, F., Cantero, E., Lacuesta, M. \& Moncaleán, P. (2012) Physiological response to drought in radiata pine: Phytohormone implication at leaf level. Tree Physiology, 3: 435-449.

5. Dionisio-Sese, M.L. \& Tobita, S. (1998) Antioxidant responses of rice seedlings to salinity stress. Journal of Plant Science, 135: 1-9.

6. Glick, B.R. (2012) Plant growth-promoting bacteria: mechanisms and applications. Scientifica, 3: $1-15$.

7. Guo X, Li T, Tang K, Liu RH (2012). Effect of germination on phytochemical profiles and antioxidant activity of mung bean sprouts (Vigna radiata). J Agric Food Chem 60: 11050-11055

8. Hartree, E.F. (1955) Haematin compounds. In: Paech. 197-245 in K, Tracey MV, (editors). Modern Methods of Plant Analysis. Springer, Verlag, Berlin.

9. Hayat, R., Ali, S., Amara, U., Khalid, R. \& Ahmed, I. (2010) Soil beneficial bacteria and their role in plant growth promotion: A review. Annals of Microbiology, 60: 579-598

10. Khaton, M.A., Sagar, A., Tajkia, J.E., Islam, M.S., Mahmud, M.S. \& Hossain, A. (2016) Effect of moisture stress on morphological and yield attributes of four sorghum varieties. Progressive Agriculture, 27(3): 265-271. 
11. Koenig, R. \& Johnson, C. (1942) Colorimetric Determination of Phosphorus in Biological Materials. Industrial and Engineering Chemistry Analytical Edition, 14 (2): 155-156.

12. Kumar, R. \& Kuhad, M.S. (2003) Fertilizer Induced Amelioration in Chickpea of Nitrogen Fixation under Moisture Stress. Annals of Arid Zone, 42: 141-146.

13. Mafakheri. A., Siosemardeh, A., Bahramnejad. B., Struik, P.C., Sohrabi, Y. (2010) Effect of drought stress on yield, proline and chlorophyll contents in three chickpea cultivars. AJCS, 4(8):580-585.

14. Majeed, S., Akram, M., Latif, M., Ijaz, M. \& Hussain, M. (2016) Mitigation of drought stress by foliar application of salicylic acid and potassium in mungbean (Vigna radiate L.). Legume Research, 39: 208-214.

15. Mohammad, I., Yadav, B.L. \& Ahamad, A. (2017) Effect of Phosphorus and Bio-Organics on Yield and Soil Fertility Status of Mungbean Vigna radiata ( L.) Wilczek Under Semi- Arid Condition of Rajastha India. International Journal of Current Microbiology and Applied Sciences, 6(3): 1545-1553.

16. Quinto, C., Arthikala, M. \& Nava, N. (2015) Effect of Rhizobium and arbuscular mycorrhizal fungi inoculation on electrolyte leakage in Phaseolus vulgaris roots overexpressing RbohB. Plant Signaling \& Behaviour, 10: 1-4.

17. Raina, S.K., Govindasamy, V. \& Kumar, M. (2016) Genetic variation in physiological responses of mungbeans (Vigna radiata L. wilczek) to drought. Acta Physiologiae Plantarum, 38: 263-275

18. Rambabu, B., Padma, V., Thatikunta, R. \& Sunil, N. (2016). Effect of drought stress on chlorophyll content and anti-oxidant enzymes of green gram genotypes (Vigna Radiata L.). Nature Environment and Pollution Technology, 4(15): 1205-1208.

19. Rebouças, D., De Sousa, Y., Bagard, M., Costa, J., Jolivet, Y., De Melo, D. \& Repellin, A. (2017) Combined Effects of Ozone and Drought on the Physiology and Membrane Lipids of Two Cowpea (Vigna unguiculata (L.) Walp) Cultivars. Plants, 14(6): 1-18.

20. Rodrigues, C.A., Bonifacio, A., Emanuel, J., Antunes, L., Albenisio, J. \& Barreto, V. (2013) Minimization of oxidative stress in cowpea nodules by the interrelationship between Bradyrhizobium sp. and plant growth-promoting bacteria. Applied Soil Ecology, 64: 245-251.

21. Sawhney, V. \& Singh, D.P. (2002) Effect of chemical desiccation at the post anthesis stage on some physiological and biochemical change in flag leaf of contrasting wheat genotypes. Field Crop Research, 77: 1-6.

22. Sharma, A. \& Dhanda, S. (2014) Abiotic Stress Response in Vigna radiata L. (mungbean). International Journal of Life Sciences Biotechnology and Pharma Research, 3: 1-11. 
23. Shobhkhizi, A., Rayni, M.F., Barzin, H.B., Noori, M. (2014). Influence of drought stress on photosynthetic enzymes, chlorophyll, protein and relative water content in crop plants. International Journal Bioscience.5 (7):89-100.

24. Tairo, E.V, Mtei, K.M. \& Ndakidemi, P.A. (2017) Influence of water stress and rhizobial inoculation on the accumulation of chlorophyll in Phaseolus vulgaris (L.) cultivars. International Journal of Plant and Soil Sciences, 15: 1-13.

25. Tint, M., Moe, A., Sarobol, E., Nakasathein, S. \& Chai-aree, W. (2011) Differential responses of selected soybean cultivars to drought stress and their drought tolerant attributions. Journal of Natural Sciences, 582: 571-582.

Table 1: Effect of soil moisture and rhizobial isolates on biochemical parameters of mungbean

\begin{tabular}{|c|c|c|c|c|c|c|c|c|c|}
\hline \multirow[t]{2}{*}{ Treatment } & \multicolumn{3}{|c|}{ Chlorophyll content } & \multicolumn{3}{|c|}{ MSI (\%) } & \multicolumn{3}{|c|}{ LHB content } \\
\hline & IR & $\mathrm{RF}$ & Mean & IR & $\mathrm{RF}$ & Mean & IR & $\mathrm{RF}$ & Mean \\
\hline RDF ( $N$ and $P$ ) & 3.93 & 3.88 & 3.91 & 13.04 & 10.82 & 11.93 & 1.92 & 1.40 & 1.66 \\
\hline RDF + Vigna703+P-36 & 4.22 & 4.14 & 4.18 & 15.81 & 12.16 & 13.99 & 2.03 & 1.46 & 1.75 \\
\hline RDF + MR 63 & 5.00 & 4.82 & 4.91 & 20.91 & 17.84 & 19.38 & 2.65 & 2.03 & 2.34 \\
\hline RDF + MR 54 & 4.31 & 4.17 & 4.24 & 17.32 & 14.35 & 15.84 & 2.23 & 1.68 & 1.96 \\
\hline RDF + MB 17a & 4.75 & 4.64 & 4.70 & 19.25 & 16.57 & 17.91 & 2.42 & 1.89 & 2.16 \\
\hline RDF + MH 8b2 & 4.34 & 4.14 & 4.24 & 17.93 & 14.72 & 16.33 & 2.13 & 1.64 & 1.89 \\
\hline Mean & 4.43 & 4.30 & & 17.38 & 14.41 & & 2.23 & 1.68 & \\
\hline $\mathrm{CD}(\mathrm{P}=\mathbf{0 . 0 5})$ & $\begin{array}{l}E=0 \\
E \times T=\end{array}$ & $\begin{array}{l}10 ; \mathrm{T}= \\
0.37\end{array}$ & & $\begin{array}{l}\mathrm{E}=1.1 \\
\mathrm{E} \times \mathrm{T}=\end{array}$ & $\begin{array}{l}\mathrm{T}=2.04 ; \\
71\end{array}$ & & $\begin{array}{l}E=0 \\
E \times T=\end{array}$ & $\begin{array}{l}\mathrm{T}=0 . \\
8\end{array}$ & \\
\hline
\end{tabular}

* E=Environment, $\mathrm{T}=$ Treatment, $\mathrm{NS}=$ Non significant, $\mathrm{IR}=$ Irrigated, $\mathrm{RF}=\mathrm{Rainfed}$

Table 2: Effect of soil moisture and rhizobial isolates on nitrogen and phosphorus content in straw and seeds of mungbean

\begin{tabular}{|c|c|c|c|c|c|c|c|c|c|}
\hline \multirow[t]{2}{*}{ Treatment } & \multicolumn{3}{|c|}{$N(\%)$ in Seed } & \multicolumn{3}{|c|}{$\mathbf{N}(\%)$ in Straw } & \multicolumn{3}{|c|}{$P(\%)$ in Seed } \\
\hline & IR & $\mathrm{RF}$ & Mean & $\overline{I R}$ & $\mathrm{RF}$ & Mean & IR & $\mathrm{RF}$ & Mean \\
\hline RDF ( $N$ and $P$ ) & 3.44 & 3.30 & 3.37 & 1.84 & 0.98 & 1.41 & 0.29 & 0.19 & 0.24 \\
\hline RDF + Vigna703+P-36 & 3.56 & 3.46 & 3.51 & 1.96 & 1.07 & 1.52 & 0.34 & 0.20 & 0.27 \\
\hline RDF + MR 63 & 4.06 & 3.86 & 3.96 & 2.40 & 1.45 & 1.93 & 0.55 & 0.30 & 0.43 \\
\hline RDF + MR 54 & 3.62 & 3.48 & 3.55 & 2.18 & 1.18 & 1.68 & 0.38 & 0.22 & 0.30 \\
\hline RDF + MB 17a & 3.82 & 3.64 & 3.73 & 2.27 & 1.39 & 1.83 & 0.46 & 0.26 & 0.36 \\
\hline RDF + MH 8b2 & 3.61 & 3.47 & 3.54 & 2.13 & 1.22 & 1.68 & 0.38 & 0.24 & 0.31 \\
\hline Mean & 3.69 & 3.54 & & 2.13 & 1.22 & & 0.40 & 0.24 & 0.32 \\
\hline $\mathrm{CD}(\mathrm{P}=0.05)$ & \multicolumn{3}{|c|}{$\begin{array}{l}\mathrm{E}=0.06 ; \mathrm{T}=0.01 ; \\
\mathrm{E} \times \mathrm{T}=0.07\end{array}$} & \multicolumn{3}{|c|}{$\begin{array}{c}\mathrm{E}=0.03 ; \mathrm{T}=0.06 ; \\
\mathrm{E} \times \mathrm{T}=0.08\end{array}$} & \multicolumn{3}{|c|}{$\begin{array}{c}\mathrm{E}=0.01 ; \mathrm{T}=0.01 ; \\
\mathrm{E} \times \mathrm{T}=0.02\end{array}$} \\
\hline
\end{tabular}

